\title{
Rectal Tubulovillous Adenoma
}

Ryan T. Hoff, DO; Asif Lakha, MD

From the Gastroenterology

Fellowship at Advocate

Lutheran General Hospital in

Park Ridge, Illinois.

Financial Disclosures: None

reported.

Support: None reported

Address correspondence to

Ryan T. Hoff, DO, Advocate

Lutheran General Hospital,

1775 Dempster St, Park Ridge,

IL 60068.

Email: ryan.hoff@

advocatehealth.com

Submitted

May 5, 2019;

revision received

May 15, 2019;

accepted

May 21, 2019.

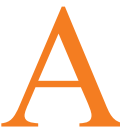

45-year-old woman presented to the clinic with hematochezia. She described

2 years of intermittent, painless, smallvolume rectal bleeding after bowel movements, without weight loss or constipation. She had no family history of colon cancer. A colonoscopy revealed a large rectal polyp (image $\mathbf{A}$ ) with gyrus-like pits, which were well visualized with narrow-band imaging (image B). Endoscopic ultrasonography demonstrated no submucosal invasion. A polypectomy was performed piecemeal via endoscopic mucosal resection using an injectable liquid compound (SIC-8000) for submucosal lift. Histologic analysis confirmed a tubulovillous adenoma, $4.8 \mathrm{~cm}$ in the greatest dimension. The hematochezia resolved following polypectomy.

Colon polyps account for nearly $13 \%$ of rectal bleeding in outpatients. ${ }^{1}$ A tubulogyrus surface pattern of polyps suggests adenomatous histology. ${ }^{2}$
When found, adenomas should be resected because of the risk of malignant transformation. SIC-8000 is a Food and Drug Administration-approved agent for submucosal injection during endoscopic mucosal resection and is a safe and potentially more effective alternative to saline. ${ }^{3}$ (doi:10.7556/ jaoa.2020.024)

\section{References}

1. Helfand M, Marton KI, Zimmer-Gembeck MJ, Sox HC Jr. History of visible rectal bleeding in a primary care population. Initial assessment and 10-year follow-up. JAMA. 1997;277(1):44-48. doi:10.1001/jama.1997.03540250052031

2. Rastogi A, Keighley J, Singh V, et al. High accuracy of narrow band imaging without magnification for the real-time characterization of polyp histology and its comparison with high-definition white light colonoscopy: a prospective study. Am J Gastroenterol. 2009;104(10):2422-2430. doi:10.1038/ ajg.2009.403

3. Repici A, Wallace M, Sharma $P$, et al. A novel submucosal injection solution for endoscopic resection of large colorectal lesions: a randomized, double-blind trial. Gastrointest Endosc. 2018;88(3):527-535.e5. doi:10.1016/j.gie.2018.04.2363

(๑) 2020 American Osteopathic Association
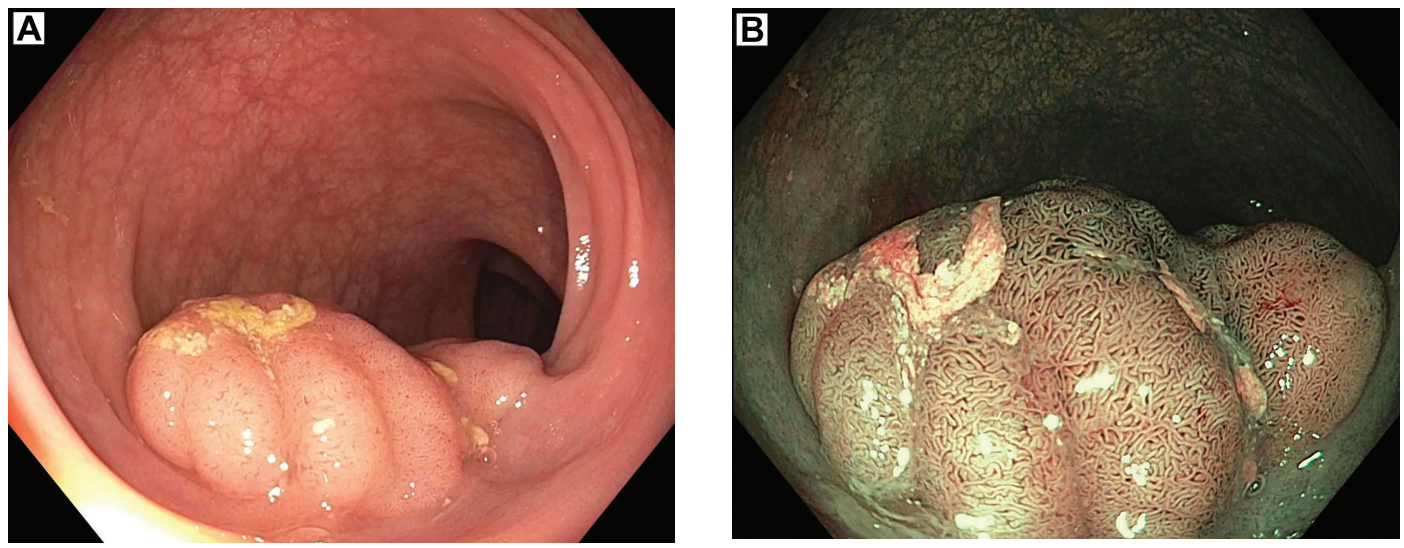